\title{
Capability Distribution between Allies, Geographical Proximity and Alliance Duration
}

\author{
Jaewook Chung
}

This study explores how geographical proximity and power distribution between allies interact and affect alliance duration. Morrow (1991), based on the security-autonomy trade-off model, claims that asymmetric alliances are likely to last longer than symmetric ones. This paper, however, argues that the effect of the relative power distribution between allies on alliance duration can be conditional upon the distance between allies because geographical proximity between allies may serve to aggravate or dampen the autonomy concerns of allied states-for example, one ally may be concerned about the mounting influence of its alliance partner and this concern could be severe in case of unequal alliances because of presumably the overwhelming influence of the former on the latter, but this kind of concern may be alleviated if the two allies are geographically remote. By contrast, in case of symmetric alliances, the equal power status between allies may relieve such autonomy concerns but geographical remoteness between them may impede the effective and efficient operation of alliances. Hence, this study hypothesizes that geographically remote and unequal alliances are more likely to last longer than geographically close and unequal alliances and that geographically close and equal alliances are more likely to last longer than geographically remote and equal alliances. These hypotheses are put to test against the allied-dyad data covering the period of 1816-2002 and I find strong support for these hypotheses. However, the findings in the robustness check suggest that these findings be accepted with some reservation especially in the case of bilateral alliances.

Key Words: Alliance duration, Geographical proximity, Equal or unequal alliances, Autonomy concern

* Jaewook Chung (jwchungir@gmail.com) is currently a lecturer at International Relations Department at Kyonggi University and a visiting research fellow at the Institute of International Studies, Seoul National University. He earned his Ph. D degree in Political Science from Rice University, Houston, Texas. His research interests include international security, especially military alliances, Northeast Asian security affairs, international political economy, quantitative research and game theory. His research appeared in the Korean Journal of International Studies.

This article is a modified version of Chapter 2 in my $\mathrm{Ph}$. D dissertation with the same title at Rice University, 2014. An earlier version of this paper was also presented at the 2013 Midwestern Political Science Association Conference on April 13, 2013. I am grateful to Ashley Leeds, Cliff Morgan, Richard Stoll, and Steven Lewis, who served as my dissertation committee members and provided me with valuable advice and comments. In particular, my special thanks go to Ashley Leeds for her encouragement and advice as dissertation committee chair. I also appreciate three anonymous reviewers for their helpful comments. Definitely, I am solely responsible for all remaining errors. 


\section{INTRODUCTION}

In his 1991 article, Morrow, based on the security-autonomy trade-off model that emphasizes the nature of the trade of security for autonomy (or vice versa) between allies, argues that asymmetric alliances are likely to last longer than symmetric alliances, implying that alliances unequal in power are more durable than alliances equal in power because the former type of alliance "strikes a more stable bargain of interest" than the latter (Morrow 1991, 905). This study intends to extend Morrow's research with some theoretical modifications. Specifically, I argue that the effect of power distribution between allies on alliance duration can be conditional upon the distance between them because the geographical distance between allies may function as a factor that aggravates or mitigates autonomy concerns (i.e. concerns about the mounting influence of an alliance partner, especially of a stronger ally, on domestic and foreign policy of the weaker state) that allied states may have. By taking this autonomy concern into account, this study hypothesizes that geographically remote and unequal alliances are more likely to last longer than geographically close and unequal alliances and that geographically close and equal alliances are more likely to last longer than geographically close and unequal alliances. To test these hypotheses, this study uses the Correlates of War (COW) data and the Alliance Treaty Obligations and Provision (ATOP) data, covering all allied dyads from 1816-2002.

The results from the Cox proportional hazard model lend strong support to the hypotheses presented in this study. I find that geographically distant and unequal allied dyads last longer than geographically close and unequal dyads. I also find that equal and geographically close allied dyads tend to last longer than equal and geographically distant dyads. Overall, the empirical findings exhibit the distinct effect of power distribution between allies on the pattern of alliance duration depending on the distance between allies. While equal alliances tend to endure when the allied states are geographically close, unequal alliances tend to endure when the allied states are geographically remote. However, the findings in the robustness check suggest that these findings be accepted with some reservation especially in the case of bilateral alliances.

The remainder of this paper is organized as follows: In the next section I review prior studies on alliance duration with a focus on Morrow's argument, and then elaborate on my theoretical arguments. In the third section, I provide the research design. In the fourth section, I present the results from duration analysis. In the fifth section, I check the robustness of the empirical findings in the study. In the final section, I conclude with a summary of the findings in this study. 


\section{HOW POWER DISTRIBUTION AND DISTANCE BETWEEN ALLIES INTERACT?}

In his 1991 article, Morrow offers a security-autonomy trade-off model as an alternative to the realist claim that alliances are formed to aggregate capabilities against a threat (e.g. Walt 1984). Morrow (1991) points out that the realist view fails to provide an adequate account of why strong states form alliances with weak states that are not expected to make a significant contribution to the aggregated capabilities of the alliance. The security-autonomy trade-off model is designed to explain this puzzle. His central claim is that an asymmetric type of alliance is formed and maintained because it can provide different kinds of benefit to the allied members-the stronger side gains additional autonomy and the weaker side additional security-as opposed to a symmetric type of alliance, which provides the same type of benefit to the allies-either security or autonomy. ${ }^{1}$

Then, what does his autonomy-security trade-off model imply as to the duration of alliances? Morrow's security-autonomy trade-off model attaches great importance to the distribution of capabilities between allies associated with the sustenance of an alliance, as opposed to the realist view seeing the presence of threat as the main cause of the persistence of alliances. This different view leads to a different conclusion regarding which type of alliance lasts longer. Morrow argues that asymmetric alliances are likely to last longer than symmetric alliances. This argument is opposite to what the realist can derive from the capability aggregation approach. For example, Walt (1997) argues that asymmetric alliances are less likely to endure than symmetric ones because a weaker side's little contribution to the alliance in terms of capabilities. Its marginal contribution will lead the weak state to question the commitment of the strong side to defend it if attacked. That is, the weaker state's fear to be abandoned by its stronger ally may facilitate a breakup of the alliance (Walt 1997, 160). In this regard, Walt posits that asymmetric alliances are less durable than symmetric ones. Morrow argues otherwise: Symmetric alliances are less likely to endure than asymmetric ones because of its sensitivity to capability change. When there is an increased capability in one member of a symmetric alliance, the state with increased capabilities may want to terminate the alliance treaty, seeking to increase military spending for self-defense rather than rely on the alliance. Put another way, symmetric alliances are sensitive to changes in military capabilities. However, Morrow argues that this logic does not necessarily hold

\footnotetext{
${ }^{1}$ Morrow (1991, 908-9) defines security as the ability to maintain the status quo while he defines autonomy as the ability to change the status quo.
} 
for asymmetric alliances. A weaker state's increased military capabilities, for example, may not affect the evaluation of the existing alliance because such an increase in capabilities is less likely to significantly alter the nature of the trade between the asymmetric allies. Therefore, this asymmetric relationship between allies, which is complementary in nature, makes the alliance ties more robust, resultingly making this type of alliance last longer than that of symmetric alliance(Morrow 1991, 918).

Empirical studies testing this relationship tend to support Morrow's claim.(e.g. Morrow 1991; Bennett 1997; Leeds and Savun 2007; Leeds, Mattes and Vogel 2009). Nonetheless, these empirical findings still leave room for the possibility that the relationship could be conditional. The strength of the findings has been varied depending on model specifications and estimation methods. These empirical findings may suggest that the effect of power (a)symmetry on alliance duration can be conditional upon certain other factors, one of which this study suspects to be the geographical distance between allies.

In this regard, this study intends to extend Morrow's (1991) research by arguing that the effect of the unequal distribution of capabilities between allies is conditional upon the geographical proximity between them. Some scholars referred to the importance of geographical proximity in alliance relationships. For example, Liska (1962) made an interesting argument, saying, "A weaker power will be commonly anxious to seek alignment with geographically remoter powers; the tendency will be only intensified if it has cultural differences with the more powerful neighbor." $(1962,13)$ However, this is a passing remark, with no further elaboration added to this statement. Here I develop a similar argument but based on a different logic.

I assume that there is a trade-off in maintaining alliance relationships. That is, a state would prefer a stronger ally over an equal ally in terms of capabilities but would prefer an equal ally to a stronger ally in terms of autonomy. Here, by autonomy I mean a state's ability to shape its policy without external influence. ${ }^{2}$ In the face of this trade-off, geographical distance may have a different meaning to an equal and an unequal alliance, respectively. To begin with, I argue that in asymmetric alliances the geographical distance between allies can play a buffer role that mitigates or aggravates the autonomy concern of the weaker state that the stronger ally may exert an excessive influence on its domestic and foreign policy.

Then, how can the geographical proximity between allies vary such an autonomy concern?

\footnotetext{
${ }^{2}$ It is important to note that the definition of autonomy made here is different from Morrow's (1991).
} 
First, in asymmetric alliances, the geographical proximity between allies can exacerbate the entrapment problem (Snyder 1984; Snyder 1997). Suppose that a weak state is in alliance with a strong state. The weak state could be concerned that its autonomy could be compromised by its stronger ally's demand and influence. It may be concerned that it could be embroiled in a conflict that its stronger ally is involved in. In fact, in asymmetric alliances, the weaker state is assumed to be more concerned about abandonment than entrapment by its stronger partner (Snyder 1984; Snyder 1997), and this fear of abandonment is one of the major reasons why the weaker state seeks to align with the stronger partner's policy. But in unequal and geographically proximate alliances, the entrapment problem of weak states can also be severe. Even though the contribution of the weaker ally to the alliance is limited in terms of capabilities, its marginal contribution to the alliance will be greater than the contribution that would be provided by a remote and weak ally. For example, the proximate and weak state is more likely to be requested to provide not only military support but also logistic support or a military foothold that its stronger partner may call for.

An Iranian case during World War II may illustrate this point. Iran signed alliance treaties with Britain and the Soviet Union in January 1942. In fact, this treaty was preceded by Iran's defeat in the military conflict initiated by these two great powers who had sought to secure the oil fields and supply lines in Iran from Germany (Cossa 1990). The resulting alliance treaty required Iran to support the two great powers in every possible means of communication including railways, roads, ports, etc (Great Britain Foreign and Commonwealth Office 1952, 1018). If Iran had failed to fulfill the commitment, it could have been a victim of another attack by its allies. Of course, Britain was a remote ally, but the Soviet Union at that time shared the border with Iran. ${ }^{3}$ This seems to be rather an extreme case, but nevertheless suggests that a weak ally may be more vulnerable to the influence of its stronger ally if it is geographically close and this will in turn make the weak state more concerned about its autonomy.

Second, when the stronger ally is geographically close, the weaker state may even perceive its stronger ally, albeit it is an ally, as a threat (Walt 1997, 158-159). In advancing his balance-of-threat theory, Walt (1987) includes geographical proximity as a component of threat. Extending his logic implies that weak states may find a proximate and stronger ally to be more threatening than a remote and strong one. If any conflict of interests between them occurs, the weak state may be concerned about any military action which is more likely in the case of a

3 After the collapse of the Soviet Union, Russia no longer shares the border with Iran. Now Azerbaijan is adjacent to Iran. 
stronger and proximate ally. This possibility of being attacked by its stronger ally induces the weaker ally to be more compliant with its stronger ally in terms of its policy, resultingly further compromising its autonomy. Although it seems rare that an allied state attacks its alliance partner, sometimes this is the case. ${ }^{4} \mathrm{In}$ addition, granted that major powers form asymmetric alliances to control weaker allies, this concern could be heightened between proximate allies (Morrow 1991; Schroeder 1976; Pressman 2008; Mattes 2012). For instance, in 1968, the Soviet Union invaded its ally Czechoslovakia, a member of the Warsaw Pact, to trample on the domestic political reform pushed for by Czech political leaders. Walt (1987) also points out that the geographical distance between the U.S. and its European allies helped mitigate such a concern as opposed to the threat that the Soviet Union posed to its allies. Walt writes:

"The United States, by contrast, has only two countries on its borders. Neither is especially powerful. Because U.S. policy toward both has been benevolent in recent decades, both have chosen to ally with the United States. Even more important, the United States is separated by two oceans from the other vital centers of world power. For the middle level powers of Western Europe and Asia, the United State is the perfect ally. Its aggregate power ensures that its voice will be heard and its actions will be felt, and it is driven by its own concern for Soviet expansion to contribute substantially to its allies' defense. At the same time, the United States is far enough away so as not to pose a significant threat to these allies. Thus the United States is geographically isolated but politically popular, whereas the Soviet Union is politically isolated as a consequence of its geographic proximity to other states." (Walt 1987, 277; my emphasis)

Then, one may be tempted to ask why this type of alliance-close and unequalcomes into being in the first place? If an alliance formed is a rational response to a security threat, then a termination of an alliance can be explained primarily by changes in internal and/or external factors that alter the preferences of the allied states and that induce them to reassess the value of the alliance (e.g. Leeds and Savun 2007). In this regard, a question may arise as to how geographical distance, a factor that is constant over time, ${ }^{5}$ can affect alliance termination. I argue that although the geographical distance between allies does not change

4 Bueno de Mesquita (1981) argues that allied states are more likely to fight each other than nonaligned states. However, empirical evidence about this argument is mixed (e.g. Ray 1990; Bremer 1992; Bearce et al. 2006).

5 There are some cases where the distance between countries changes due to changes in the border. But since such cases are relatively unusual, I do not take them into consideration. 
over time, the perception of autonomy concerns can be affected by the distance and this perception may change in response to the ally's behavior. If the distance between allies is close in an asymmetric alliance, the weaker state could be more sensitive than those with remote allies to the behavior of its stronger ally. I posit that a weaker state's concern about its autonomy can be dormant at the formation stage (i.e. the weaker state may be uncertain about the stronger ally's intention). However, this type of alliance is more susceptible to termination because of the dormant risk and its sensitivity. In this regard, this type of alliance can be a more fragile type of alliance than that of unequal and distant alliance even if the stronger ally was the best choice available at the time of alliance formation for the weaker state.

Although geographical closeness intensifies the concern of weaker states in asymmetric alliances, things may be different for a weaker state with a stronger ally located in the distance. In general, it may be the case that an ally remote from its alliance partner could be limited in providing for security to its ally. However, this would not be necessarily the case for a weak state with a strong ally. Even though the strong ally is located in the distance, its power projection capabilities may allow it to sustain a deterrent effect on the weak state's (potential) adversary (Boulding 1962). From the weaker side's perspective, the distant ally could be beneficial in both senses. It could still capitalize on the deterrent effect that its strong ally creates, but would be relatively less concerned about the influence of its strong ally. However, one may argue that it can still pose a threat to its weaker ally given the stronger ally's power projection capabilities. That could be true. However, even if a strong state wants to discipline its weaker ally by using force, it could be more costly for the stronger and distant ally than for the stronger and close ally to rely on such an coercive option. Thus, disputes between unequal and distant allies are more likely to be settled in a peaceful manner. Again here I do not intend to argue that geographical remoteness eliminates the autonomy concerns of weaker states in absolute terms, but that it would mitigate such concerns in relative terms. Consequently, the distance can serve as a buffer that mitigates the concern that the weaker side harbors over its stronger ally. This conjecture leads to the first hypothesis of this study:

\section{Hypothesis 1: Geographically remote and unequal alliances are more likely to last longer than geographically proximate and unequal alliances.}

Then what role does the geographical distance between allies play in symmetric alliances and how does it affect alliance duration? In the case of symmetric alliances, allied states are less likely to be concerned about the influence of their partner because power parity may allow them to be less concerned about its 
partner's unilateral influence, making the issue of autonomy loss less severe. Instead, allied states in symmetric alliances are more likely to be concerned with capabilities that the other can provide for security. For this reason, they may find geographically proximate allies more attractive than those that are geographically distant. Again, the distance can convey different meanings to different types of alliances. For equal alliances, remoteness may operate as an obstacle to maximizing capability aggregation effects; on the other hand, for unequal alliances, remoteness may serve as a buffer that could mitigate the autonomy concern of the weaker side. Therefore, other conditions equal, equal alliances that are geographically close seem to last longer than equal alliances that are geographically remote. This argument leads to the second hypothesis of this study:

Hypothesis 2: Geographically proximate and equal alliances are more likely to last longer than geographically remote and equal alliances.

Table 1. Which Type of Alliance Lasts Longer

\begin{tabular}{lccc}
\hline & & \multicolumn{2}{c}{ Geographical Proximity } \\
\hline \multirow{2}{*}{ Power Status } & Proximate & Remote \\
& Enual & $\mathrm{A}$ & $\mathrm{B}$ \\
& Unequal & $\mathrm{C}$ & $\mathrm{D}$ \\
\hline
\end{tabular}

The $2 \times 2$ matrix of Table 1 illustrates the arguments advanced above. In terms of the probability of alliance duration, I predicted that $\operatorname{Pr}(\mathrm{D})>\operatorname{Pr}(\mathrm{C}),{ }^{6}$ meaning that given unequal power distribution between allies, geographically distant alliances tend to last longer than geographically close ones, as elaborated earlier for Hypothesis 1 . I also predicted that $\operatorname{Pr}(\mathrm{A})>\operatorname{Pr}(\mathrm{B})$, meaning that given equal power between allies, geographically close alliances tend to last longer than geographically distant ones, as elaborated earlier for Hypothesis 2. Along the line of the logics advanced above, I also predict that $\operatorname{Pr}(\mathrm{A})>\operatorname{Pr}(\mathrm{C})$, meaning that given the geographical proximity between allies, equal alliances are likely to last longer than unequal alliances. The rationale for this argument goes as follows: Provided that allied states are located geographically close, equal allies have less concern about autonomy than unequal allies (in particular, the weaker side of the unequal alliance) and this will render managing the alliance ties less costly. In addition, equal allies will also capitalize on their geographical proximity to enhance their efficiency gains through economies of scale, for example (Morgan and Palmer

${ }^{6}$ Here I denote $\operatorname{Pr}(*)$ by the probability that a certain type of alliance endures. 
2003; Palmer and Morgan 2011). Although unequal alliances can also enjoy the benefits of economies of scale, given the weaker state's little contribution to the overall capabilities, the efficiency-generating effect of unequal alliances will be much weaker than that of equal alliances. Furthermore, geographical proximity can exacerbate the autonomy concern of the weaker state, making the alliance less stable. For the reasons mentioned above, I present the third hypothesis.

Hypothesis 3: Geographically close and equal alliances are more likely to last longer than geographically close and unequal alliances.

Finally, I predict that $\operatorname{Pr}(\mathrm{D})>\operatorname{Pr}(\mathrm{B})$, meaning that given the geographical remoteness between allies, unequal alliances tend to last longer than equal alliances. Provided that allied states are located geographically distant, weaker states in unequal alliances can enjoy the deterrent effects that their stronger allies provide and suffer less from autonomy concerns. On the other hand, equal allies that are geographically distant find it hard to combine their capabilities in an efficient manner. ${ }^{7}$ For this reason, I offer the fourth hypothesis.

Hypothesis 4: Geographically remote and unequal alliances are more likely to last longer than geographically remote and equal alliances.

However, I do not predict any relationship either between $\operatorname{Pr}(\mathrm{A})$ and $\operatorname{Pr}(\mathrm{D})$ or between $\operatorname{Pr}(\mathrm{B})$ and $\operatorname{Pr}(\mathrm{C})$ because it is indeterminate in the logics presented above.

\section{RESEARCH DESIGN}

\section{DATA AND VARIABLES}

To test the hypotheses presented above, I use a series of datasets commonly used in quantitative studies in IR, including the Correlates of War (COW), Alliance Treaty Obligations and Provisions (ATOP) (Leeds, Ritter, Mitchell and Long 2002), and POLITY IV (Marshall, Gurr and Jaggers 2010). All of the datasets used in this study are retrieved by using the EUGene program developed by Bennett and Stam (2000). The spatial and temporal domain of this study covers all allied-dyads from 1816 to 2002. Accordingly, the unit of analysis of this study is an allied-dyad year.

7 If both allies are major powers in the case of equal alliances, this efficiency problem could be ameliorated given their power projection capabilities. However, given the entire set of equal alliances involving both major-major and minor-minor powers, the validity of my argument can hold. 
Since this study requires analyzing the duration of alliances, event-history analysis is employed as an estimation method.

\section{DEPENDENT VARIABLE}

Alliance Termination: The dependent variable of this study is alliance termination. In order to code alliance termination, it is first necessary to operationalize alliances. In this study, I use the ATOP data (Leeds et al. 2002) to operationalize alliances. The ATOP data classifies alliances into five types: defense, offense, consultation, neutrality and nonaggression. ${ }^{8}$ Among these five types of alliances, I take only defense pacts into consideration because only defensive alliances are consistent with the arguments made here. ${ }^{9}$ Since this study employs an allied dyad year as the unit of analysis, it is necessary to describe in detail how alliance termination is coded. ${ }^{10}$ If a pair of states is at least the member of either form of alliance, bilateral or multilateral in a given year, it is counted as an allied dyad in a given year. This means that even if one of their alliance relationship terminates, it is still in an allied relationship if the dyad maintains the other alliance relationship. A dyad in an allied relationship in a given year is coded zero, and when the allied relationship ends in a year, that end year is coded one. Thus, more precisely, in this study, alliance termination means the end of an allied relationship between a pair of states.

It is worth noting here how I code some cases where allied dyads no longer exist

\footnotetext{
8 It is important to note that these five types of alliances are not necessarily mutually exclusive, however.

9 For example, here I argue that weaker states benefit from deterrent effects generating from forming an alliance with major powers. These deterrence effects is plausible only when states include a provision for defense in their agreement (Johnson and Leeds 2011). In addition, I also emphasize that capability aggregation effects matter in symmetric alliances. This capability aggregation will occur only in defensive or offensive alliances. These two things considered together, the relevant type of alliance to be considered for analysis is a defense type of alliance. For this reason, in testing the hypotheses of this study, I confine my attention to defense pacts.

${ }^{10}$ In fact, using an allied dyad year as the unit of analysis generate two concerns. First, it can make the allied dyads from multilateral alliances overrepresented in the sample. While a bilateral alliance generates one dyad per year, a multilateral alliance composed of 5 states, for example, generates 10 (nondirected) dyads per year. This study assumes that even in multilateral alliances, bilateral relationships among the allies matter and affect their decision on alliance duration. If this assumption holds to a large extent, the overrepresentation is not a serious problem. However, if this assumption does not hold, the empirical findings could be misleading. Second, since most of the prior studies except for Gaubatz (1996) use an alliance-year as the unit of analysis, the empirical findings derived from those studies may not be compatible with the findings from this study. The reason why I adopt the dyad as a unit of analysis despite these concerns is that one of the key independent variables in this study is the distance between allies, which is primarily meaningful in a dyadic relationship.
} 
due to the loss of independence by either state in a dyad. ${ }^{11}$ Even though alliance relationships end due to the loss of independence, these cases cannot be simply considered as terminated as long as the loss of independence has nothing to do with the allied relationships..$^{12}$ Thus, I code these cases as censored rather than terminated if a state's loss of sovereignty is not affected by its dyad relationship. For example, South and North Yemen were unified into one country in 1990. But they had no allied relationship. In this case, each country's allied dyads before unification are coded as right censored. But if one country is merged into its existing ally (e.g. Prussia's unification), I coded them as terminated. In fact, most of the cases are code as censored and the Prussian unification is the only set of cases that I code as terminated. ${ }^{13}$

In sum, the dependent variable is dichotomous. In the original dyad-year ATOP data, a pair of states in a defense pact in a given year is coded 1 ; otherwise missing. To make the data coding amenable to duration analysis, I recode 1 to 0 if a pair of states is in an allied relationship in a given year, and code 1 in a year when the allied relationship ends. This coding rule resulted in 1,165 termination years of allied dyads out of 42,589 all allied-dyad years.

\section{INDEPENDENT VARIABLES}

Unequal Alliance: To capture the distribution of capabilities between allies, I rely on whether an allied state is a major or minor power. The COW data classifies all nations into two types, major and non-major based on historians' opinion (Krause and Singer 2001). Using this COW classification of major power status, I define an allied dyad as an equal alliance if both countries belong to the same type of major power status, and otherwise as an unequal alliance. Accordingly, of the three possible combinations, major-major, minor-minor, and major-minor, the first two types of allied dyads, major-major and minor-minor, are coded as an equal alliance, and the third type as an unequal alliance. However, since this study covers the Cold-War period, this classification can be somewhat questionable because it is hard to consider the two superpowers, the United States and the Soviet Union, as equal vis-à-vis other major powers. To address this

11 The ATOP dataset provides information about the modes of alliance termination. The TERMMODE variable coded at the member level defines six modes of alliance termination (Leeds 2005). I used that information to code the cases mentioned here.

12 However, in the ATOP coding, in cases where states lost their independence due to their ally's failure to fulfill the commitment, they are coded as violation. Naturally, those dyads in which either state lost independence by the other side's violation are coded as terminated.

13 In fact, how I code them did not change the estimation results. Even when I coded all these cases as terminated, the estimation results remained almost the same. 
problem, I follow Morrow's $(1991,921)$ classification of major powers. The United States and the Soviet Union are classified as superpowers from 1945. The Soviet Union (Russia), however, ceases to be coded as a superpower after 1989, while the United States' superpower status remains intact from 1945 on. To take this superpower status into consideration, I code superpowers as 2, major powers as 1 and minor powers as 0 , and subtract one nation's score from the other. Then I code unequal alliances as 1 if the absolute value of the subtracted scores is equal to either 1 or 2 , and equal alliance as 0 if the subtracted score is equal to zero. In sum, the unequal alliance is coded one while the equal alliance is coded zero, serving as the reference for this binary variable.

Distance: There are several distance measures in the COW data to capture the distance between countries, and among them, I use a measure of the distance between two capitals, accounting for contiguity. This measure allows considering the distance between two countries and contiguity as well (Bennett and Stam 2007, 23). Since this measure codes zero for a pair of states that shares land borders, the zero distance is highly meaningful in a substantive sense, meaning contiguity. Since the unit of measure is a mile, the effect of this variable on the dependent variable will be too small. To avoid this problem, I rescale it into 1000 miles. That is, the unit of measure is 1000 miles.

\section{CONTROL VARIABLES}

Joint Democracy: Gaubatz's (1996) study suggests that joint regime type may also influence the duration of alliances. In particular, his study suggests that joint democratic dyads tend to last longer than mixed or non-democratic dyads. In line with Gaubatz's argument, Reed (1997) also tests whether democratic regime types affect alliance duration, and finds that the higher percentage of democracies in an alliance renders the alliance less likely to dissolve. Bennett's (1997) empirical test encompassing alternative alliance duration models also confirms the positive relationship between liberal democracies and alliance duration. Leeds and Savun's work (2007) shows more clearly that democratic regimes' commitment to abide by an international agreement is associated with a longer lifespan of alliances associated with and/or formed by democracies. By setting the dependent variable as alliance termination in the form of violation of the terms of an agreement, they test whether democratic regimes are more likely to adhere to international agreements, and the empirical result showing a strong negative relationship between the number of democracies in a bilateral alliance and alliance termination lends strong support to the hypothesis. For these reasons, it is necessary to include a joint regime type variable in the model as a 
control variable. To operationalize the joint regime type, this study uses Polity2 scores from the Polity IV data (Marshall, Gurr and Jaggers 2010), which range from -10 to 10 with lower scores indicating less democratic regimes. To make a joint democracy variable dichotomous, I code a pair of countries as joint democracy $(=1)$ if both countries have a Polity2 score equal to or higher than 6 in a given year; otherwise zero. Following Gaubatz (1996) and the other studies mentioned above, I expect that democratic allied dyads are more durable than non-democratic allied dyads.

Change in Capabilities: Most of the studies on alliance duration emphasize the effect of changes in capabilities on alliance duration and empirical results also support these arguments because changes in capabilities lead allied states to alter the valuation of the alliance (Morrow 1991; Bennett 1997; Leeds and Savun 2007). However, it is difficult to predict whether an increase in the capabilities of a member state can increase the likelihood of alliance termination because capability change has a different meaning depending on the alliance type and the power status in the alliance in question. For example, in an asymmetric alliance, the weaker states' increased capabilities may increase the likelihood of termination if they seek to gain more autonomy; on the other hand, in the same type of alliance the stronger side's decreased capabilities may be associated with alliance termination. By contrast, in a symmetric alliance, either side's decrease in capabilities may be strongly associated with alliance termination. Since either an increase or a decrease in the capabilities of allied states can alter the value of the alliance, I control for this effect by considering the absolute changes in the capabilities of member states. That is, to capture the effect of capability change in allied dyads, whether it is an increase or a decrease, I use an absolute capability change measure. Specifically, using the COW CINC score, I calculate a percentage change in the capabilities of each state in a dyad from the year of alliance formation following Leeds and Savun (2007). ${ }^{14}$ Since the CINC score basically captures the relative capabilities of a state in the system in a given year, this measure allows us to capture how much relative capability change has occurred to each member state since the formation of the alliance. Then, it is formulated as follows:

$$
\text { change in capabilities }=\frac{\left|c_{a p}-c_{t} a p_{t 0}\right|}{c a p_{t 0}}
$$

(Here $t$ denotes the current year and tothe year of alliance formation)

14 Actually, Leeds and Savun (2007) use a dummy variable for this capability change setting up a threshold value such as a 10 percent change coded as one and otherwise zero. I followed the same path, but when I used a dummy variable for this measure, in empirical tests the significance of the coefficient changed depending on its threshold value. So I choose a continuous measure here. 
This coding rule generates a capability change rate for each individual state in a given year. Of the two rates from each ally, I choose the higher rate as representing the capability change rate of that allied dyad in a given year because I assume that the higher percentage change in capabilities may have a stronger impact on alliance termination.

Change in Threat: An external threat could be an important factor that influences not only alliance formation but also alliance duration (Walt 1987, 1997). We anticipate that as an external threat declines, alliances are more likely to end. To control for this effect of an external threat, here I use a threat measure developed by Leeds and Savun (2007). They define an external threat in terms of the external security environment. According to them, an external threat is measured by summing up the capabilities (CINC scores) of "potentially threatening" states in the politically relevant region (contiguous states and major powers in the system) (Maoz 1996) Here a certain state's "potentially threatening states" refer to those who do not share foreign policy interests and who are not alliance partners in the politically relevant region. For example, state $\mathrm{A}$ is a potential threat to state $\mathrm{B}$ if state $\mathrm{A}$ is in the same politically relevant region, and shares a low level of foreign policy similarity and it is not an ally to state B. In their study, foreign policy similarity is operationalized by the unweighted global S scores (Signorino and Ritter 1999), whose scores below a threshold level (0.775) are defined as a low level of similarity. This study uses a threat measure by slightly modifying their measure. Since the face validity of S scores is somewhat dubious, ${ }^{15}$ I use only information regarding the politically relevant region and alliance ties without incorporating $S$ scores in calculating the threat level. Thus, those countries in the politically relevant region that are not any types of allies (based on the ATOP data) are regarded as potentially threatening states and their capabilities (CINC scores) are summed up. Using this CINC score as a threat level an allied country faces, I calculate the change in threat that each country in an allied dyad faces. As done in calculating capability change, the change in threat was calculated as a

15 For example, according to the unweighted S scores, South Korea shares the highest S score with North Korea (.962) while sharing the lowest S score with the U.S.(.431) among the countries in the politically relevant region. I think this happens because $\mathrm{S}$ scores is calculated based on the assumption that the distance between countries reduces foreign policy similarity. This is not a reasonable assumption, but including S scores as a component in calculating a state's threat level may end up considering a friendly country as an enemy. In South Korea's case, incorporating S scores into the calculation of threat levels may end up coding the U.S. as an enemy for instance. For this reason, I do not consider unweighted S scores as a component in calculating threat levels. Instead, I include weighted S scores, which show better face validity than unweighted S scores, as a control variable to control for foreign policy similarity. 
percentage change in threat from the year of alliance formation. But this time, I allow for a negative percentage change (as opposed to capability change) because I anticipate that a positive increase in threat will reduce the likelihood of alliance termination. Consequently, the change in threat is calculated as follows:

$$
\text { change in threat }=\frac{\text { threat }_{t}-\text { threat }_{t 0}}{\text { threat }_{t 0}}
$$

(Here $t$ denotes the current year and $t 0$ the year of alliance formation)

This coding rule generates a percentage change in threat for each individual state in a given year. Of the two, I choose the higher rate as representing the threat change of that allied dyad in a given year. I expect that a high percentage change in threat is negatively associated with the likelihood of alliance termination.

Foreign Policy Similarity: It is generally accepted that alliances are formed when they share common security interests. The strength of this common interest is reflected in their foreign policy. If allied dyads share common interests and their foreign policy is similar, then we can expect that those allied dyads will last longer than other dyads that share weaker common interests. Signorino and Ritter's (1999) $\mathrm{S}$ scores are a measure of foreign policy similarity based on alliance portfolios, ranging from - 1 (dissimilarity) to 1 (similarity). I use global weighted S scores as a control variable because of presumably the better face validity of the weighted $S$ scores than global unweighted $S$ scores. ${ }^{16}$ Since this measure is built upon alliance portfolios, the termination of an alliance in a year can be represented in the measure of foreign policy similarity in the same year. This may cause an endogeneity problem. To avoid this problem, I take a one-year lag for this variable.

Wartime Alliance: Some alliances are formed during wars. These kinds of alliances, called wartime alliances, can outlive wars but can be terminated with the end of the wars because they fulfilled their purposes. Thus, I control for the effects of wartime alliances. The ATOP dataset provides information regarding wartime alliances. The ATOP dataset codes alliances as a wartime alliance if any one of the alliance members is involved in a war at the time of alliance formation. Following this coding rule, I code an alliance dyad whose member (either or both) is a participant in a war at formation as a wartime alliance. In case of multilateral alliances, if neither of the member states in a dyad is a participant of a war, it is not coded as a wartime alliance. For example, suppose that there is a multilateral

16 See fn.15. for detail. 
alliance composed of three states $\mathrm{A}, \mathrm{B}$, and $\mathrm{C}$. If state $\mathrm{A}$ is involved in a war at the time of formation, then $(\mathrm{A}, \mathrm{B})$ and $(\mathrm{A}, \mathrm{C})$ dyads are coded as a wartime alliance. But $(\mathrm{B}, \mathrm{C})$ dyad is not coded as a wartime alliance. The ATOP coding sheets provide more detailed information about which state is a war participant and I rely on this information to code this variable. The wartime alliance variable is thus a binary variable. If a dyad is a wartime alliance in a given year, it is coded one; otherwise zero. I expect that wartime alliances are more likely to terminate than non-wartime alliances.

Multilateral Alliances: The unit of analysis in this study is an allied-dyad year. However, in many cases allied dyads are part of multilateral alliances, and the size of an alliance may affect the duration of the alliance, and especially a large scale of multilateral alliances. NATO is a case in point. To take this institutional effect into consideration, I consider whether an allied dyad belongs to a bilateral or multilateral alliance by relying on the information provided by the ATOP dataset. The ATOP dataset provides information about how many bilateral or multilateral alliances an allied dyad shares in a given year. But, sometimes, an allied dyad shares both bilateral and multilateral alliances and this makes it difficult to group allied dyads simply into bilateral or multilateral alliances. Given this problem, I classify allied dyads in a given year into three groups: pure bilateral year, pure multilateral year and sharing both bilateral and multilateral year. I use pure multilateral year as a baseline. But here I do not make any specific prediction as to which type of alliance, bilateral or multilateral, will last longer than the other.

Finally, Table 2 presents descriptive statics for the variables used in this statistical analysis.

Table 2. Descriptive Statistics

\begin{tabular}{lrrrrr}
\hline \multicolumn{1}{c}{ Variables } & \multicolumn{1}{c}{ Mean } & \multicolumn{1}{c}{ SD } & Min & Max & \multicolumn{1}{c}{ Obs } \\
\hline Alliance Termination & .027 & .163 & 0 & 1 & 42589 \\
Unequal Alliance & .159 & .367 & 0 & 1 & 45289 \\
Distance (in 1000 miles) & 1.761 & 1.728 & 0 & 11.91 & 45289 \\
Joint Democracy & .258 & .437 & 0 & 1 & 33069 \\
Change in Capabilities & 81.654 & 125.193 & 0 & 1196.552 & 42589 \\
Change in Threat & 30.316 & 66.548 & -86.942 & 474.613 & 42589 \\
Foreign Policy Similarity & .917 & .198 & -.577 & 1 & 40371 \\
Wartime Alliance & .071 & .257 & 0 & 1 & 45289 \\
Share Bilateral Alliances Only & .032 & .176 & 0 & 1 & 45289 \\
Share Bi and Multilateral Alliances & .044 & .207 & 0 & 1 & 45289 \\
\hline
\end{tabular}




\section{ESTIMATION METHOD}

Since this study involves analyzing the duration/termination of alliances, the event history model is amenable to this analysis. There are several parametric models such as exponential or Weibull distribution models, and a semi-parametric model such as the Cox proportional hazard model. Among them, I choose the Cox proportional hazard model for estimation because it allows us to leave duration dependence unspecified (Box-Steffensmeier and Jones 2004). Since the temporal domain of this study extends to 2002, many allied dyads that continue to exist after 2002 are right-censored. In addition, since the data structure is time-series cross-sectional (TSCS), it is necessary to control for possible unit heterogeneity across allied dyads. To address this problem, I use robust standard errors in estimation.

In using the Cox proportional hazard model, it is necessary to check whether the proportional hazard assumption holds. When the proportional hazard assumption was checked, it turned out that there are severe violations of the Cox proportional hazard assumption in the model. Although the set of the key independent variables meet the proportional hazard assumption, most of the control variables violate the proportional hazard assumption. This suggests that the effects of these control variables vary rather than remain intact over time. One remedy to this problem is to take a time interaction with these variables so that the suppressed time-varying effects can present themselves (Box-Steffensmeier, Reiter and Zorn 2003). To this end, I take time interaction terms with these control variables, which include the set of variables such as joint democracy, capability change, threat change, foreign policy similarity, and bilateral/multilateral alliance type. In this regard, this analysis adopts a nonproportional hazard model.

\section{EMPIRICAL RESULTS AND ANALYSIS}

In Table 3, the results from the Cox hazard regression model are presented. Here I present the results from two models. Model 1, which ignores the time-varying effects of the control variables by not including interaction terms, is presented for reference to show the extent to which the effects of the key independent variables on alliance duration are affected by the different model specification. ${ }^{17}$

17 When the proportional hazard assumption is violated, the coefficients with the proportional hazard problem as in Model 1 can be understood as representing the average or aggregate effect of these variables on duration. By "average", it means the aggregated effect of the initial effect and the time varying effect of the variable of interest (Allison 1995). In this regard, the results reported in Model 1 are still informative, however. 
Hence, in what follows, I focus my discussion on Model 2 that considers the time-varying effects of the control variables by including time-interaction terms.

Now look at the results reported in Model 2. It is worth noting that since I use the Cox proportional hazard model for analysis, positive coefficients indicate the greater likelihood of termination while negative coefficients indicate less likelihood of termination. Hypothesis 1 indicates that unequal and distant alliances last longer than unequal and close alliances. I find strong support for this hypothesis. The coefficient for the interaction term is negative and statistically significant at .01 level, meaning that an unequal and distant allied dyads are less likely to terminate. Hypothesis 2 suggests that in the case of equal alliances, geographically close alliances tend to last longer than geographically remote ones. The estimated coefficient indicates the conditional effect of the distance between allies when they are equal in terms of power. This hypothesis is also borne out by the coefficient for the distance variable that is positive and statistically significant, indicating that given the equal power between allies, the more proximate allied dyads tend to last longer.

I also hypothesized (Hypothesis 3 ) that geographically close and equal allied dyads are more durable than geographically close and unequal dyads primarily because of the autonomy concern of the weaker states in unequal dyads. Based on this hypotheses, I expect a positive sign for the Unequal Alliance coefficient. As in Hypothesis 2, the estimated coefficient indicates the conditional effect of capability distribution between allies when they are contiguous (Distance=0). I find strong support for this hypothesis as well. The sign of Unequal Alliance is positive and highly statistically significant as predicted. Finally, consider whether Hypothesis 4 is supported or not. I hypothesized that geographically distant and unequal dyads last longer than geographically distant and equal dyads. This hypothesis can be checked by looking at the interaction coefficients and the distance coefficients. In Model2, the interaction term is negative and the distance coefficient positive, indicating that unequal and distant allied dyads tend to last longer than equal and distant dyads.

Table 3. The Effect of the Distribution of Capabilities and Distance between Allies on Alliance Duration: Cox Non-proportional Hazard Model

\begin{tabular}{lrr}
\hline & Model1 & \multicolumn{1}{c}{ Model2 } \\
\hline Main & & \\
Unequal Alliance & $0.601^{* * *}$ & $0.535^{* * *}$ \\
& $(0.139)$ & $(0.144)$ \\
Unequal x Distance & $-0.137^{* * *}$ & $-0.136^{* * *}$ \\
& $(0.028)$ & $(0.028)$
\end{tabular}




\begin{tabular}{|c|c|c|}
\hline & Model1 & Model2 \\
\hline Distance (in 1000 miles) & $\begin{array}{r}0.107^{* * *} \\
(0.014)\end{array}$ & $\begin{array}{r}0.098^{* * *} \\
(0.014)\end{array}$ \\
\hline Joint Democracy & $\begin{array}{r}-0.809^{* * *} \\
(0.126)\end{array}$ & $\begin{array}{r}-0.582^{* * *} \\
(0.147)\end{array}$ \\
\hline Capability Change & $\begin{array}{r}-0.003^{* * *} \\
(0.001)\end{array}$ & $\begin{array}{r}0.001 \\
(0.001)\end{array}$ \\
\hline Threat Change & $\begin{array}{r}-0.012^{* * *} \\
(0.001)\end{array}$ & $\begin{array}{r}-0.017^{* * *} \\
(0.002)\end{array}$ \\
\hline Foreign Policy Similarity & $\begin{array}{r}-0.871^{* * *} \\
(0.104)\end{array}$ & $\begin{array}{r}-0.779^{* * *} \\
(0.112)\end{array}$ \\
\hline Wartime Alliance & $\begin{array}{r}1.388^{* * *} \\
(0.100)\end{array}$ & $\begin{array}{r}1.320^{* * *} \\
(0.105)\end{array}$ \\
\hline Bilateral Alliance Only & $\begin{array}{r}0.121 \\
(0.175)\end{array}$ & $\begin{array}{l}-0.234 \\
(0.210)\end{array}$ \\
\hline Bi or Multilateral Alliance & $\begin{array}{r}0.256 \\
(0.156) \\
\end{array}$ & $\begin{array}{l}-0.418 \\
(0.288) \\
\end{array}$ \\
\hline \multicolumn{3}{|c|}{ Time-Varying Covariates (TVC) } \\
\hline Joint Democracy & & $\begin{array}{l}-0.011 \\
(0.011)\end{array}$ \\
\hline Capability Change & & $\begin{array}{r}-1.84 e^{-04^{* * *}} \\
\left(6.47 e^{*}-05\right)\end{array}$ \\
\hline Threat Change & & $\begin{array}{r}3.70 \mathrm{e}-04^{* * *} \\
(7.45 \mathrm{e}-05)\end{array}$ \\
\hline Foreign Policy Similarity & & $\begin{array}{r}-0.028^{*} \\
(0.016)\end{array}$ \\
\hline Bilateral Alliance Only & & $\begin{array}{r}0.039 * * \\
(0.013)\end{array}$ \\
\hline Bi or Multilateral Alliance & & $\begin{array}{r}0.055^{* * *} \\
(0.013)\end{array}$ \\
\hline Observations & 31540 & 31540 \\
\hline Log Likelihood & -6038.928 & -6012.244 \\
\hline No. of Allied Dyads & 1808 & 1808 \\
\hline Failures & 960 & 960 \\
\hline Chi-Squared & 1149.406 & 1235.394 \\
\hline
\end{tabular}

Standard errors in parentheses; ${ }^{* *} p<0.01,{ }^{* *} p<0.05,{ }^{*} p<0.1$

Now look briefly at the effects of control variables on alliance duration. By and large, the effects of the control variables do not deviate much from our expectation. Joint democracy is less likely to terminate, alliance dyads with similar foreign policy interests also last longer, and wartime alliances tend to terminate earlier. An increased external threat to either side of an allied dyad tends to decrease the likelihood of termination at the initial stage but this 
tendency is reversed over time. This result is somewhat puzzling. Changes in capabilities have no discernible effect at the initial stage on alliance termination but does affect it as time passes. It reduces the likelihood of termination rather than increase it. This could be puzzling in one sense but is understandable in another given that here the change is operationalized as either an increase or a decrease in capabilities. Although alliance type variables (Sharing both bilateral and multilateral alliance and sharing only bilateral alliances) are not significant at all in Model 1, it turns out that they have significant time-varying effects on alliance termination as shown in Model 2. The result shows that at the initial stage allied dyads in bilateral alliances are little different from those in multilateral alliances in terms of the risk of termination but over time allied dyads in bilateral alliances are more exposed to the risk of termination than those only in multilateral alliances.

Although Table 2 presents whether the estimated coefficients are significant or not, it is not enough to show the substantive effects of these key independent variables on alliance duration. To make the presentation more intuitively appealing, I provide scatter plots in Figure 1 that illustrate how predicted hazard rates change over distance in response to the distribution of capabilities between allies (King, Tomz and Wittenberg 2000).

Figure 1. The Difference in Alliance Duration between Equal and Unequal Alliances Depending on Distance

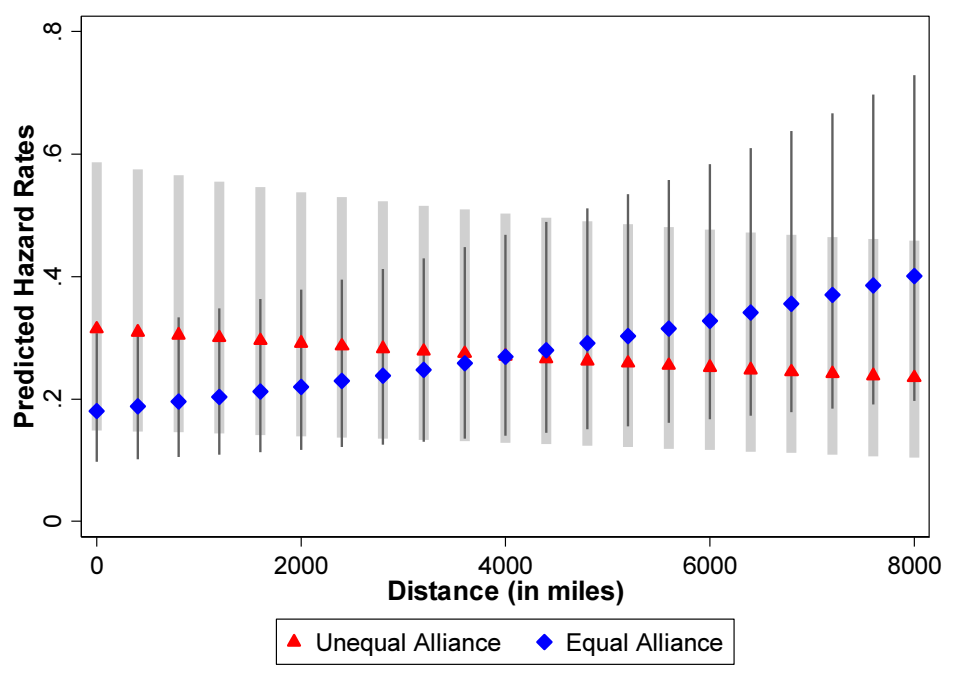


As illustrated in Figure 1, the $\mathrm{Y}$ axis indicates predicted hazard rates and the $\mathrm{X}$ axis represents the distance between allies. The diamond-shaped points represent the mean values of predicted hazard rates for equal alliances, and the triangle-shaped points represent the mean values of predicted hazard rates for unequal alliances. The vertical bars from the mean values represent the 95 percent confidence intervals for the predicted mean values. The predicted hazard rates are calculated by substituting the mean value of each independent variable into the equation. To account for the time-varying effects of the control variables, I draw this graph when the alliance duration is at $\mathrm{t}=19$, which is the mean value of the alliance duration years in the sample.

This graph illustrates that in the case of equal alliances, equal alliances tend to face higher risks of termination as the distance between allies becomes larger. By contrast, in the case of unequal alliances, they face a lower risk of termination as the distance between them grows larger. Earlier, I argued that the distance has a different meaning to an equal and an unequal alliance. For an equal alliance, the distance can serve as an obstacle to efficacy in aggregating capabilities while for an unequal alliance, it can serve as a buffer to the autonomy concern of the weaker state. The steepness of the slope may indicate the degree of this different effect. The steep and upward curve for equal alliances indeed indicates the extent to which the symmetric alliance is aimed at power aggregation and efficiency. The steep downward slope for unequal alliances implies that the buffering effect and the power projection capabilities of major powers matter in maintaining asymmetric alliances.

It is worth pointing out here that most of the alliances are located relatively closely. The mean value of the distance is 1761 miles, and thus a more meaningful range of the distance between allies is within 6000 miles although the maximum distance in the sample is 11910 miles. ${ }^{18}$ In addition, given that the standard errors of the predicted values are large as the long confidence intervals suggest, it is necessary to check whether these differences in predicted hazard rates between equal and unequal alliances are statistically significant. For this purpose, I run another simulation, and the resulting plots are shown in Figure 2.

18 The standard deviation of the distance equals 1728 miles. If I sum up the mean value and two-standard deviation, it is 5217 miles. The 95 percentile is 4817 miles and the 99 percentile is 8503 miles. 
Figure 2. The Difference in Alliance Duration between Equal and Unequal Alliances in the Meaningful Range of Distance

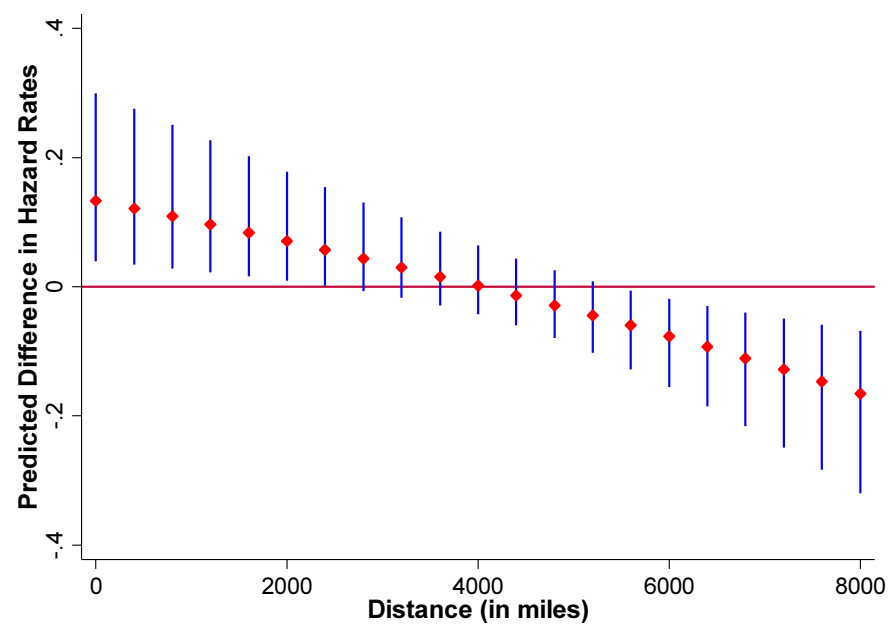

In Figure 2, the diamond-shaped points represent the differences in the predicted hazard rates between unequal and equal alliances and the vertical lines represent the $95 \%$ confidence intervals. Thus, the positive points indicate the greater likelihood of termination of unequal alliances than that of equal alliances because $\operatorname{Pr}$ (termination | unequal alliances) $>\operatorname{Pr}$ (termination | equal alliances) while the negative points represent otherwise. For example, the first vertical line with the positive point at distance $=0$ indicates the following: the predicted probability of termination in the case of unequal alliances is higher than that of equal alliances and this difference in the predicted probability is statistically significant given that it does not touch the zero horizontal line.

In this regard, Figure 2 illustrates that unequal alliances face a higher risk of termination than equal alliances when the distance between them is less than 2800 miles. However, these differences in the risk of termination between the two types become insignificant between 2800 and 5200 miles. Beyond that distance, unequal alliances face a lower risk of termination than equal alliances. That is, unequal alliances are more likely to terminate in the close distance than equal alliances but less likely to terminate in the long distance than equal alliances. Therefore, this allows us to conclude that the interaction effect between power distribution and geographical proximity is significant in the meaningful range of distance.

Now, Table 4 presents substantive effects, illustrating the extent to which the predicted hazard rate changes in response to a one-unit change in an independent variable. ${ }^{19}$ In fact, the estimated coefficients in Table 2 are not easy to interpret 
in an intuitive manner. By contrast, hazard ratios obtained by exponentiating the estimated coefficients are more intuitively appealing. As shown in Table 2, what is most striking is the effect of unequal alliance on alliance termination. If a contiguous allied dyad changes from an equal to an unequal alliance, the risk of termination increases by as much as $70.7 \%$. This suggests that a change in the power status of a neighboring ally exerts a great impact on the sustenance of the existing alliance.

Before proceeding to the substantive effect of distance and the interaction terms, it is worth recalling that the unit of measure for distance is 1000 miles. Thus, a one-unit increase in distance means a 1000 mile increase in distance. As reported in Table 4, a one-unit increase in distance, given that allied dyads are equal in power, results in about a $10 \%$ increase in the hazard rate. This is why we observe the relatively steep and upward curves in Figure 1 in the case of equal alliances. These steep and upward curves for equal alliances imply that equal alliances lose efficiency as the distance between them increases. Again, this confirms the view that symmetric alliances are more inclined towards capability aggregation. However, when there are increases in both power status and distance, it decreases the hazard rate by $12.7 \%$.

Table 4. Substantive Effects

\begin{tabular}{lc}
\hline \multicolumn{1}{c}{ Variables } & Model 2 \\
\hline Unequal Alliance & $70.7 \%$ increase \\
Unequal Alliance X Distance & $12.7 \%$ decrease \\
Distance & $10.2 \%$ increase \\
\hline
\end{tabular}

\section{ROBUSTNESS CHECKS}

In what follows, I will briefly discuss the results from robustness checks of the empirical findings in this study. To see how robust the findings in this study are, I run additional six models with different model specifications. ${ }^{20}$

To begin with, the first three models is intended to test whether the empirical

19 In Table 4, I include only the key independent variables.

${ }^{20}$ In specifying these models for robustness checks, I generally followed the reviewers' suggestions. In addition, in running models, I used the simple model not considering time-interaction effects because here we are most concerned with how the key independent variables of this study perform in different model specifications. 
findings are robust regardless of the number of alliances. To this end, the all alliance dyads are divided into three groups: bilateral alliances without multilateral agreements, bilateral alliances with multilateral agreements, and multilateral alliances without bilateral agreements. The results are shown in Table 5. Perplexingly, when purely bilateral alliances are only included in the sample, I find no support for the hypotheses as in Model 1 . Besides, the signs of the coefficients for the three key independent variables are opposite to what the hypotheses predicted, ${ }^{21}$ and some of them are statistically significant. These results may suggest that the arguments made in this study actually do not hold for bilateral alliances, attenuating the validity of the theoretical claims made here. However, it seem a little premature to conclude that the argument made here does not hold at all for bilateral alliances. Let us look at the result from Model 2, which also includes bilateral alliances. Model 2 shows what happens when alliance dyads with both bilateral and multilateral alliances are considered. In some sense, these alliance dyads can be viewed as bilateral alliances; and in another sense, as multilateral ones. Interestingly enough, these eclectic types of alliance dyads exhibit a pattern of alliance behavior that confirms the hypotheses. The two coefficients for Distance and the interaction term are highly statistically significant while the coefficient for Unequal Alliance is moderately supported. The third model includes purely multilateral alliances. As the results show, these alliance dyads with multilateral alliances lend strong support to the hypotheses. In sum, although it is rather dubious whether the cases of bilateral alliances support the hypotheses, those of multilateral alliances provide strong support to the hypotheses.

The next two models, Models 4 and 5, test whether the results remain intact over the temporal domain. I divide the temporal domain into two periods: the pre-second world war and the post-second world war period, with the former corresponding roughly to the multipolar world and the latter to the bipolar world (e.g. Waltz 1964). What is interesting in the results is that the results from Model 4 are similar to those from Model 1 and the results from Model 2 are to those from Model 5. In other words, the results from Model 4 do not support the hypotheses while those from Model 5 do. Finally, I check whether the results are robust when the key independent variable, Unequal Alliance, which is a dichotomous, discrete variable, is replaced with a continuous variable, labeled Power Gap. ${ }^{22}$ As the results from Model 6 show, despite the fact that the coefficient for Unequal

\footnotetext{
${ }^{21}$ In order for the hypotheses to be supported, we anticipate positive signs for the coefficient for Unequal Alliance, and for Distance, and a negative sign for the interaction term.

${ }^{22}$ To create this continuous measure displacing Unequal Alliance, I used CINC scores and simply subtracted one country's CINC score (cap1) from the other's (cap2) and took the absolute value of this subtraction.
} 
Alliance is no longer statistically significant, there doesn't seem to be a serious problem when the measure has been changed. The sign of Unequal Alliance is positive, slightly short of statistical significance; the other coefficients show high statistical significance.

Then, it is necessary to consider how to reconcile these results with the theoretical claims offered here. Why are the hypotheses supported primarily in the cases of multilateral alliances and for the post second world war period? At this point, frankly speaking, I do not believe that I can offer a satisfactory answer to this mixed finding. But I conjecture that if the findings are not simply relegated to a statistical artifact, my theoretical argument might capture the alliance patterns of the bipolar world after World War II, especially divided between the North Atlantic Treaty Organization (NATO) centered on the United States and the Warsaw Pact centered on the Soviet Union. As cited earlier, while the United States was geographically distant from its allies, posing less of a threat to its allies, the geographical proximity of the Soviet Union to its allies may have posed a serious threat to them (Walt 1987).

Then, why are we unable to find the pattern of alliance duration in bilateral alliances described earlier?; on the contrary, the empirical results from bilateral alliances only suggest the opposite pattern, posing new puzzles to solve. The results from Model 1 suggest that equal alliances in the distance tend to last longer, and unequal alliances in the distance tend to end earlier. Then, can this pattern of alliance duration be considered as defining features of bilateral alliances? Of course, we cannot preclude such a possibility, but I would say probability not. Above all, Model 2 including bilateral alliances shows a pattern of alliance duration conforming to the hypotheses presented in this study. ${ }^{23}$

Then, what explains this rather indistinct pattern of alliance behavior? Definitely, this question begs for further research, but my conjecture is that the indistinct pattern of alliance duration in the case of bilateral alliances might have something to do with the flexibility of bilateral alliances, especially in conjunction with multipolarity, a system-level variable. Institutionalists argue that more institutionalized alliances tend to endure (Keohane 1988; Bennett 1997). This implies that bilateral alliances are more flexible than multilateral ones. In the sample data used for this study, the mean duration of bilateral-only alliances is 14 years, while the value for pure multilateral alliances is 19 years. ${ }^{24}$

23 Although not reported here, the analyses made by combining allied dyads from Model 1 and from Model 2 showed no distinct pattern of alliance duration, meaning that no key independent variables were statistically significant even at the marginal level of significance. For reference, $\mathrm{z}$ values in the parentheses for each key independent variables are as follows: Unequal Alliance (0.38); Distance (-0.97); Unequal x Distance (-0.56) 
Another reason why we cannot find a distinct and stable pattern of alliance behavior may relate to polarity. ${ }^{25}$ Realists argue that in a multipolar world states are compelled to switch their alliances in a more flexible manner than in a bipolar world (e.g. Snyder 2007). This does seem to be the case: the mean duration of bilateral-only alliances in the multipolar period (prior to 1945) is no more than 9.7 years. If my conjecture does hold, to some extent, then this explains why the results from the eclectic types of alliances shown in Model 2 converge to the results in Model 3 from pure multilateral alliances. Then, what can we say about alliance duration pattern proposed in this study? I would argue that the pattern of alliance duration suggested in this research may be at work and become more salient when the international system is stabilized as in a bipolar world and when the alliance arrangements are more institutionalized. The author, however, admits that this argument is ad hoc and tentative because the original study did not control for these factors-institutionalization, and polarity. Nonetheless, the author attempted to provide accounts for this result to offer directions for future research. After all, for a better understanding of this rather puzzling finding, a more sophisticated and thorough analysis will be required.

Table 5. Robustness Checks

\begin{tabular}{|c|c|c|c|c|c|c|}
\hline & Model1 & Model2 & Model3 & Model4 & Model5 & Model6 \\
\hline & $\begin{array}{l}\text { Bilateral } \\
\text { Only }\end{array}$ & $\begin{array}{c}\text { Bi \& } \\
\text { Multilateral }\end{array}$ & $\begin{array}{l}\text { Multilateral } \\
\text { Only }\end{array}$ & $\begin{array}{c}\text { Year }< \\
1945\end{array}$ & $\begin{array}{c}\text { Year > } \\
1944\end{array}$ & $\begin{array}{l}\text { Continuous } \\
\text { Ind. Var. }\end{array}$ \\
\hline Unequal Alliance & $\begin{array}{l}-0.680 \\
(0.495)\end{array}$ & $\begin{array}{l}0.601^{*} \\
(0.330)\end{array}$ & $\begin{array}{r}0.640^{* * *} \\
(0.168)\end{array}$ & $\begin{array}{r}0.194 \\
(0.233)\end{array}$ & $\begin{array}{r}0.746^{* * *} \\
(0.191)\end{array}$ & \\
\hline Distance (in 1000 miles) & $\begin{array}{r}-0.339^{* *} \\
(0.659)\end{array}$ & $\begin{array}{r}0.420^{* * *} \\
(0.105)\end{array}$ & $\begin{array}{r}0.113^{* * *} \\
(0.015)\end{array}$ & $\begin{array}{r}-0.268^{* * *} \\
(0.076)\end{array}$ & $\begin{array}{r}0.207^{* * *} \\
(0.013)\end{array}$ & $\begin{array}{r}0.095^{* * *} \\
(0.014)\end{array}$ \\
\hline Unequal $\times$ Distance & $\begin{array}{c}1.205^{*} \\
(0.662)\end{array}$ & $\begin{array}{r}-0.757^{* * *} \\
(0.179)\end{array}$ & $\begin{array}{r}-0.118^{* * *} \\
(0.030)\end{array}$ & $\begin{array}{l}0.178^{*} \\
(0.092)\end{array}$ & $\begin{array}{r}-0.152^{* * *} \\
(0.038)\end{array}$ & \\
\hline Joint Democracy & $\begin{array}{l}-0.355 \\
(0.474)\end{array}$ & $\begin{array}{l}-0.382 \\
(0.341)\end{array}$ & $\begin{array}{r}-0.848^{* * *} \\
(0.145)\end{array}$ & $\begin{array}{l}-0.407 \\
(0.302)\end{array}$ & $\begin{array}{r}-0.855^{* * *} \\
(0.153)\end{array}$ & $\begin{array}{r}-0.697^{* * *} \\
(0.123)\end{array}$ \\
\hline Capability Change & $\begin{array}{l}-0.000 \\
(0.002)\end{array}$ & $\begin{array}{l}-0.002 \\
(0.002)\end{array}$ & $\begin{array}{r}-0.003^{* * *} \\
(0.001)\end{array}$ & $\begin{array}{r}0.014 * * * \\
(0.004)\end{array}$ & $\begin{array}{r}-0.002^{* * *} \\
(0.001)\end{array}$ & $\begin{array}{r}-0.003^{* * *} \\
(0.001)\end{array}$ \\
\hline Threat Change & $\begin{array}{r}0.001 \\
(0.002)\end{array}$ & $\begin{array}{r}-0.005^{* *} \\
(0.002)\end{array}$ & $\begin{array}{r}-0.015^{* * *} \\
(0.002)\end{array}$ & $\begin{array}{r}0.007 * * * \\
(0.003)\end{array}$ & $\begin{array}{r}-0.016 * * * \\
(0.002)\end{array}$ & $\begin{array}{r}-0.012^{* * *} \\
(0.001)\end{array}$ \\
\hline Foreign Policy Similarity & $\begin{array}{r}-0.987^{*} \\
(0.570)\end{array}$ & $\begin{array}{l}-0.808 \\
(0.731)\end{array}$ & $\begin{array}{r}-0.740^{* * *} \\
(0.108)\end{array}$ & $\begin{array}{l}0.740^{*} \\
(0.445)\end{array}$ & $\begin{array}{r}-0.655^{* * *} \\
(0.080)\end{array}$ & $\begin{array}{r}-1.034^{* * *} \\
(0.103)\end{array}$ \\
\hline
\end{tabular}

\footnotetext{
${ }^{24}$ I conducted a simple t-test to see whether the difference is statistically significant, and it was highly significant at .001 level.

${ }^{25}$ One reviewer, although he or she did not explicitly allude to polarity, I believe, has this polarity in mind when he or she asked for checking the robustness.
} 


\begin{tabular}{|c|c|c|c|c|c|c|}
\hline & Model1 & Model2 & Model3 & Model4 & Model5 & Model6 \\
\hline & $\begin{array}{l}\text { Bilateral } \\
\text { Only }\end{array}$ & $\begin{array}{c}\mathrm{Bi} \& \\
\text { Multilateral }\end{array}$ & $\begin{array}{l}\text { Multilateral } \\
\text { Only }\end{array}$ & $\begin{array}{c}\text { Year }< \\
1945\end{array}$ & $\begin{array}{c}\text { Year > } \\
1944\end{array}$ & $\begin{array}{l}\text { Continuous } \\
\text { Ind. Var. }\end{array}$ \\
\hline Wartime Alliance & $\begin{array}{r}0.366 \\
(0.489)\end{array}$ & $\begin{array}{r}0.865^{* *} \\
(0.406)\end{array}$ & $\begin{array}{r}1.366^{* * *} \\
(0.114)\end{array}$ & $\begin{array}{l}-0.055 \\
(0.260)\end{array}$ & $\begin{array}{r}1.891 * * * * \\
(0.120)\end{array}$ & $\begin{array}{r}1.426^{* * *} \\
(0.101)\end{array}$ \\
\hline Bilateral Alliance Only & & & & $\begin{array}{l}-0.019 \\
(0.261)\end{array}$ & $\begin{array}{l}-0.251 \\
(0.290)\end{array}$ & $\begin{array}{c}0.299^{*} \\
(0.168)\end{array}$ \\
\hline Bi or Multilateral Alliance & & & & $\begin{array}{r}0.273 \\
(0.214)\end{array}$ & $\begin{array}{l}-0.300 \\
(0.274)\end{array}$ & $\begin{array}{r}0.363^{* *} \\
(0.146)\end{array}$ \\
\hline Power Gap & & & & & & $\begin{array}{r}1.356 \\
(0.945)\end{array}$ \\
\hline Power Gap x Distance & & & & & & $\begin{array}{r}-0.852^{* * *} \\
(0.220)\end{array}$ \\
\hline Observations & 1310 & 1802 & 28428 & 2427 & 29113 & 31540 \\
\hline Log Likelihood & -203.354 & -173.321 & -5254.320 & -644.218 & -4500.839 & -6034.499 \\
\hline No. of Allied Dyads & 114 & 150 & 1653 & 508 & 1645 & 1808 \\
\hline Failures & 57 & 51 & 852 & 147 & 813 & 960 \\
\hline Chi-Squared & 14.902 & 40.018 & 981.834 & 88.775 & 1851.544 & 1202.672 \\
\hline
\end{tabular}

Standard errors in parentheses; ${ }^{* *} p<0.01,{ }^{* *} p<0.05,{ }^{*} p<0.1$

\section{CONCLUSION}

This paper extends Morrow's study (1991) with some modifications. Morrow argues that unequal alliances are more durable than equal alliances because of their more stable give-and-take or complementary relationship. In this study I argue that the effect of the distribution of capabilities between allies on the duration of alliances can be conditional upon the distance between them because the geographical proximity between allies may function as a factor that aggravates or ameliorate autonomy concerns that allied states have. Hence, I hypothesize that geographically remote and unequal alliances are more likely to last longer than geographically proximate and unequal alliances, and that geographically close and equal alliances are more likely to last longer than geographically close and unequal alliances. These hypotheses tested against the allied-dyad data from 1816-2002 using the Cox proportional hazard model are empirically supported. ${ }^{26}$ Then what do the results we obtained here suggest?

The empirical results show that equal alliances tend to last longer when they are geographically close while unequal alliances tend to last longer when they

\footnotetext{
${ }^{26}$ However, as it turns out in the robustness checks, the limitations of this study will also be discussed below.
} 
are geographically remote. This distinct pattern of alliance duration between unequal and equal alliances suggests a few things. In the first place, the duration of equal alliances is very sensitive to the distance between them. The drastic rise of the risk of termination with the increase in the distance between equal allies may suggest that in the case of equal alliances, how to aggregate capabilities between them is a major concern and that the great distance between them reduces the value of the alliance. This may uphold Morrow's argument that symmetric alliances are primarily aimed to maximize capability aggregation effects.

Second, the argument that the geographically close and stronger ally can aggravate the autonomy concern and even can pose a threat to its weaker ally is strongly supported. The main reason for claiming a shorter duration of the geographically close and unequal alliance than that of the geographically close and equal alliance is that in the case of an unequal alliance the weaker state is concerned about the influence of the stronger ally on its policy and that this concern can be intensified proportional to the geographical proximity. If this underlying mechanism is at work, we should observe that the geographically close and unequal alliance faces a higher risk of termination than the geographically close and equal alliance as hypothesized above. The empirical findings lend strong support to the hypothesis.

Given this, it has some substantive implications. Great powers seeking to expand their power to the other regions of interest may find it less difficult and costly to look for a minor power partner and maintain its alliance ties because minor powers may also want strong sponsors in the distance. This pattern of alliance duration may partly explain how alliance networks are geographically expanded and how great powers can be involved in geopolitics in another region.

In this regard, this study makes some contribution to the literature of alliance duration by taking the geographical factor into consideration with regard to alliance duration. In particular, by linking geographical proximity with the degree of autonomy concerns on the weak side, this study highlights the significance of geographical distance that creates a different meaning to equal and unequal alliances. While for equal alliances, remoteness may serve as a negative factor that impairs efficiency, for unequal alliances it may serve as a positive factor that relieves the concern about autonomy on the weaker side. That is, in the prior studies of alliance duration, this geographical factor has been neglected or simply viewed as a negative factor that undermines the efficiency of military alliances, but this study attaches importance to this geographical factor, and shed new light on alliance behavior.

However, the results from the robustness checks urge us to put the original empirical findings under further scrutiny. In particular, we find a stable pattern 
of alliance duration in multilateral alliances but not in bilateral alliances. As discussed in the previous section, it is hard to offer a satisfactory explanation for these mixed findings. Thus, it may be necessary to explore whether bilateral alliances are different in nature from multilateral alliances, and this may require us to trace back to the process of alliance formation. Besides, we also find that alliance behavior in a multipolar world is not so stable as in a bipolar world. In this sense, how systemic level variables such as polarity operate and affect alliance behavior seems to assume a renewed significance in this topic. This study allows for a new look at alliance behavior with regard to duration but also poses a new puzzle to us.

\section{REFERENCES}

Allison, Paul D. 1995. Survival Analysis Using SAS. Cary, NC: SAS Institute Inc. Bearce, David H., Kristen M. Flanagan and Katharine M. Floros. 2006. "Alliances, Internal Information, and Military Conflict Among Member-States." International Organization 60(3), 595-625.

Bennett, D. Scott. 1997. "Testing Alternative Models of Alliance Duration, 1816-1984." American Journals of Political Science 41(3), 846-878.

Bennett, D. Scott and Allan Stam. 2000. "EUGene: A Conceptual Manual." International Interactions 26(2), 179-204. . 2007. "EUGene." Documentation V.3.2.

Boulding, Kenneth E. 1962. Conflict and Defense: A General Theory. New York, NY: Harper and Brothers.

Box-Steffensmeier, Janet M and Bradford S Jones. 2004. Event history modeling: A guide for social scientists. New York, NY: Cambridge University Press.

Box-Steffensmeier, Janet M., Dan Reiter and Christopher Zorn. 2003. "Nonproportional Hazards and Event History Analysis in International Relations." Journal of Conflict Resolution 47(1), 33-53.

Bremer, Stuart A. 1992. "Dangerous Dyads: Conditions Affecting the Likelihood of Interstate War, 1816-1965.” Journal of Conflict Resolution36(2), 309-341.

Bueno de Mesquita, Bruce. 1981. The War Trap. New Haven, CT: Yale University Press.

Cossa, Ralph A. 1990. Iran: Soviet interests, US concerns. Vol. 11. Darby, PA: Diane Publishing.

Gaubatz, Kurt Taylor. 1996. "Democratic States and Commitment in International Relations." International Organization 50(1), 109-139. 
Great Britain Foreign and Commonwealth Office. 1952. British and Foreign State Papers. Number v. 144. H.M.S.O.

Johnson, Jesse C and Brett Ashley Leeds. 2011. "Defense Pacts: A Prescription for Peace?” Foreign Policy Analysis 7(1), 45-65.

King, Gary, Michael Tomz and Jason Wittenberg. 2000. "Making the Most of Statistical Analyses: Improving Interpretation and Presentation." American Journal of Political Science 44(2), 347- 361.

Krause, Volker and J. David Singer. 2001. "Minor Powers, Alliances, and Armed Conflict: Some Preliminary Patterns.” In Erich Reiter and Heinz Gartner eds., Small States and Alliances, Vienna: Physica-Verlag, 15-23.

Leeds, Brett Ashley. 2005. "Alliance Treaty Obligations and Provisions (ATOP) Codebook: version 3.0.” Accessed at http://www.ruf.rice.edu/leeds (March 26, 2011)

Leeds, Brett Ashley and Burcu Savun. 2007. "Terminating Alliances: Why Do States Abrogate Agreements?” Journal of Politics 69(4), 1118-1132.

Leeds, Brett Ashley, Jeffrey M. Ritter, Sara McLaughlin Mitchell and Andrew G. Long. 2002. "Alliance Treaty Obligations and Provisions, 1815-1944." International Interactions 28(3), 237- 260.

Liska, George. 1962. Nations in Alliance: The Limits of Interdependence. Baltimore, MD: The Johns Hopkins Press.

Maoz, Zeev. 1996. Domestic Sources of Global Change. Ann Arbor, MI: University of Michigan Press.

Marshall, Monty G., Ted Robert Gurr and Keith Jaggers. 2010. POLITY IV Project: Dataset User's Manual. Center for Systemic Peace.

Mattes, Michaela. 2012. "Reputation, Symmetry, and Alliance Design." International Organization 66(4), 679-707.

Morgan, T. Clifton and Glenn Palmer. 2003. "To Protect and to Serve: Alliances and Foreign Policy Portfolios." Journal of Conflict Resolution47(2), 180-203.

Morrow, James D. 1991. "Alliances and Asymmetry: An Alternative to the Capability Aggregation Model of Alliances." American Journal of Political Science 35(4), 904-933.

Palmer, Glenn and T Clifton Morgan. 2011. A theory of foreign policy. Princeton, NJ: Princeton University Press.

Pressman, Jeremy. 2008. Warring Friends: Alliance Restraint in International Politics. Ithaca, NY: Cornell University Press.

Ray, James Lee. 1990. "Friends as Foes: International Conflict and Wars between Formal Allies.” In Charles S. Gochman and Alan Ned Sabrosky eds. Prisoners of War?: Nation-States in the Modern Era, Lexington, MA: Lexington Books, 73-91. 
Reed, William. 1997. "Alliance Duration and Democracy: An Extension and Cross-Validation of "Democratic States and Commitment in International Relations"”' American Journal of Political Science 41(3), 1072-1078.

Schroeder, Paul W. 1976. "Alliances, 1815-1945: Weapons of Power and Tools of Management. In Klaus Knorr ed., Historical Dimensions of National Security Problems, Lawrence, KS: University Press of Kansas.

Signorino, Curtis S. and Jeffrey M. Ritter. 1999. "Tau-b or Not Tau-b: Measuring the Similarity of Foreign Policy Positions." International Studies Quarterly 43(1), 115-144.

Snyder, Glenn H. 1984. "The Security Dilemma in Alliance Politics.” World Politics 36(4), 461-495. . 1997. Alliance Politics. Ithaca, NY: Cornell University Press.

Walt, Stephen M. 1987. The Origins of Alliances. Ithaca, NY: Cornell University Press.

. 1997. "Why Alliances Endure or Collapse." Survival 39(1), 156-179.

Waltz, Kenneth N. “The Stability of a Bipolar World.” Daedalus 93(3), 881-909.

[Received Nov 11, 2019; Revised Mar 28, 2020; Accepted Apr 6, 2020] 
